\title{
New Technologies for Fashionable Functional Clothing - Combining Model Design and Innovative Patterning
}

\author{
Jana Siegmund and Sybille Krzywinski* \\ Department of Mechanical Engineering, Technical University Dresden, Germany \\ Submission: January 30, 2018; Published: February 15, 2018 \\ *Corresponding author : Sybille Krzywinski, Department of Mechanical Engineering, Technical University Dresden, Germany, \\ Email: sybille.krzywinski@tu-dresden.dej
}

Keywords: 3D-CAD; Parametric human models; Typical posture of the sport

\section{Introduction}

The design process for ready-made textile products has made use of technologies over the last decades which have seen only minor modifications. While the textile industry with its new fibre fabrics and novel textile structures is a source of innovation for many technological developments in other sectors (lightweight construction sector with textile-reinforced plastics, civil engineering and medicine sectors), the process technologies for garment design have remained largely unchanged. Though 2D CAD applications have been brought to perfection to quite an extent, they do not close the digital IT gap between model design and patterning of a product.

In order to realise innovative products within ever shorter design cycles that meet high quality requirements at a reasonable cost, it would make sense if the design, the product function and its producibility could be assessed at an early stage of the design process. These targets are difficult to achieve without computeraided methods and modelling tools for the products and the possibility of validating product functionality by simulating virtual prototypes. 3D design and patterning methods can be an approach to gain greater transparency in the product development process.

The market for sports and lifestyle articles is booming. Now almost every kind of sport has its own special outfit. The aim is to fulfil fashion (lifestyle) and functional (high-performance sport) demands as well as those of corporate identity, with the former clear boundaries between extreme sports and leisure becoming more and more obscure.

The intention of our work is to demonstrate the possibilities of computer-aided engineering as an innovative method to link model design and innovative patterning of sportswear and functional garments to provide our own contribution there to.

\section{D product development for close-fitting sportswear/ functional garments}

Only few design fundamentals exist in the sector of closefitting garments in particular. For close-fitting wear, fit and material properties largely determine wearing comfort and functionality. Functional sportswear can only be optimised if all relevant influence factors/parameters are appropriately matched to each other.

The application of optical measuring methods in the form of 3D body scanners offers the possibility of creating a virtual 3D image of a person. The innovative idea is to use this method for a significantly improved 3D model design and patterning methodology which, based on an intuitive working principle, can do without mathematical formula for the relationship between body and 2D pattern parts. Designers and pattern maker can then concentrate on their actual task and work on the desired variety of models with the necessary functionalities in mind. Priority is given to the digital link between model design and patterning. The 3D working method offers the significant advantage that the relationship between the person "to be clothed" and the product to be developed is always present. For instance, decisions on product development then can be made as early as possible and in direct contact with top athletes on the basis of virtual prototypes and be realised within tight deadlines [1-4].

\section{Realisation and Results}

At present, the 3D reconstruction and modelling of persons is of great international interest. Human anatomy and anthropometric relationships between the body measures of a size and of different sizes are implemented computationally on a scientifically established basis. Our work at ITM has made a significant contribution to this research. 
In order to work systematically, the creative, technical and functional realisation of a product up to pattern making must be subdivided into the following steps (Figure 1):

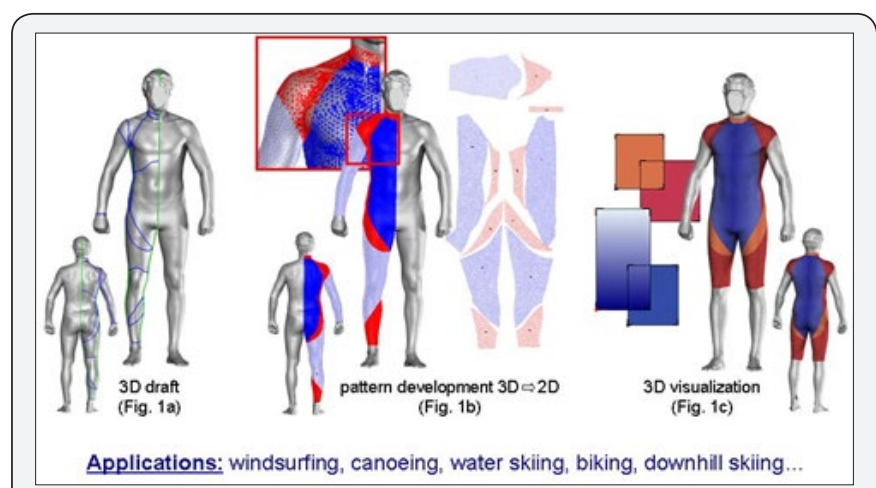

Figure 1: Process chain.

\section{Model design}

Style - definition of cut, details and material) e. g., consideration of the sport-specific functional requirements (Figure 1a).

o The working principle for close-fitting garments is based on the concept of developing the design on the virtual 3D anatomic model. Designers/pattern maker can directly draw the model and pattern part lines on the virtual body surface with drawing tools. Patterning on the 3D model to suit a specific fashion or function hardly requires any knowledge of pattern making.

o To ensure a reproducible 3D product development, design-specific measuring distances and points such as breastline, waistline and hipline are marked on the virtual 3D body and stored.

o To avoid having to redraw a model for every different size, parametric human models have been developed. These are linked to size charts and can be changed to standard sizes or individual body measures (top athletes) at the push of a button.

\section{Patterning}

Automatic derivation of the 2D pattern parts from the 3D design (Figure 1b).

o Computer-aided automatic development of pattern parts drawn in 3D and the computational link of these with the material data allows the designer, by being able to change the material to be applied, to derive with great accuracy the 2D pattern parts from a model which ensure good fit. Conventional pattern making is largely eliminated.

o Since close-fitting garments are usually worn stretched, the pattern cuts must be smaller than the respective body measures. Any tensions and stretch that occur are analysed at the computer and, if necessary, elements ensuring a better fit can be added.

\section{Visualisation of colours and designs in 3D (Figure 1c)}

Besides the definition of pattern segmentation and the resulting seam lines, the design of a model also requires a colour design. It is possible to assign colours and/or textures (fabric patterns) to the developed regions. Among the design tasks today are also the support of an own marketing business, customer product management, trend and colour information and precise production specifications. Cost control also plays an important role.

In high-performance sport it is particularly important to design garments in such a way that they offer optimal wearing comfort in the typical posture of the sport and support the athlete's performance. To be able to quantify differences in pattern construction and to make a statement on wearing comfort, garments for biking and downhill skiing were developed as examples. Besides the above-mentioned differences in posture, sport-specific body measures (e.g. strong thighs) were noticed, resulting from the targeted training of a particular group of muscles. These can be taken into account by scaling the human model accordingly. In both sports, the relevant differences are in the lengths of the front and back trunk and in a wider back. Often a product design with few seams is required (such as in downhill skiing) to order to prevent chafing of body parts by the seams. In order to create an attractive design despite this restriction, prints are applied while controlling position and aesthetic effect in 3D (Figure 2).

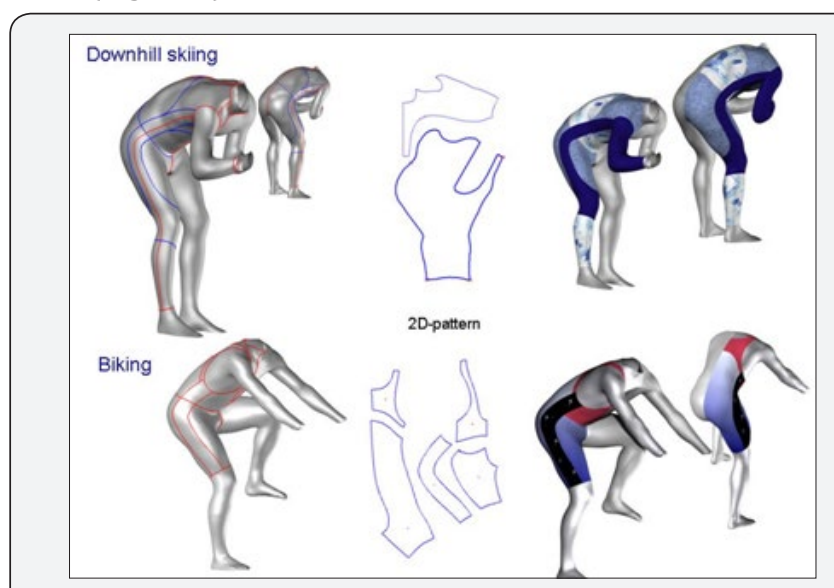

Figure 2 : Typical posture of the sport.

At present, garment systems with integrated electronics are advancing. These can continuously measure vital parameters such as ECG and heart rate, blood pressure, oxygen saturation as well as breathing and can also record the wearer's activity parameters. The virtual representation of the 3D product form and the 3D design methodology offer the possibility of placing data and power transmission lines and suitable sensors optimally in smart textile applications. Shirts and bodies with predefined points for the integration of electrodes for ECG measurement were developed as an example in order to determine the user's vital parameters. To find suitable positions for integrating the functionality of taking the user's vital parameters, the basic 
concept of the working principle is to first determine the necessary positions on the virtual mannequin, then to project these onto the 3D garments designed on it and finally to transfer them to the developed 2D pattern parts (Figure 3).

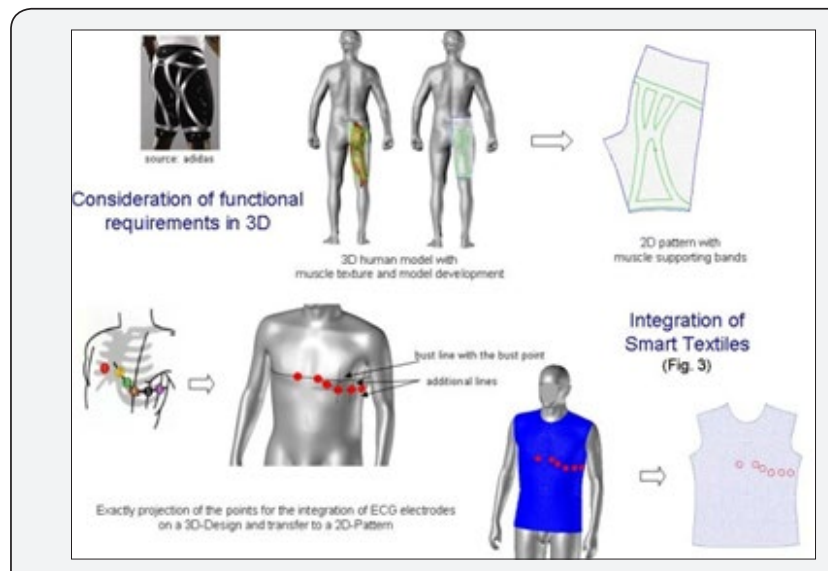

Figure 3 : Integration of Smart Textiles.
The targeted use of modern technologies can help to save up to $80 \%$ of currently required working times. Furthermore, by significantly reducing problems of fit, product quality can be improved.

\section{References}

1. Krzywinski S (2005) Verbindung von Design und Konstruktion in der textilen Konfektion unter Anwendung von CAE. Habilitationsschrift, Fakultät Maschinenwesen, TU Dresden, TUDpress, Germany.

2. Krzywinski S, Siegmund J, Wendt Ellen (2015) 3D Product Development for loose Fitting Garments Based on Parametric Human Models. 6th International Conference on 3D Body Scanning Technologies, Lugano, Switzerland, p. 27-28.

3. Siegmund J (2013) Erarbeitung virtueller Menschmodelle als Konstruktionswerkzeug zur 3D Produktentwicklung in der Bekleidungsindustrie. Dresden, Technische Universität Dresden, Fakultät Maschinenwesen, Dissertation, Dresden: TUDpress, Germany.

4. Krzywinski S, Siegmund J, Ansari N, Wendt E (2016) Digitalisierung für die Produktentwicklung von Sportbekleidung (Poster). 6. Kongress Textil Innovativ - Sport \& Gesundheit, Fürth.

Your next submission with Juniper Publishers will reach you the below assets

- Quality Editorial service

- Swift Peer Review

- Reprints availability

- E-prints Service

- Manuscript Podcast for convenient understanding

- Global attainment for your research

- Manuscript accessibility in different formats

( Pdf, E-pub, Full Text, Audio)

- Unceasing customer service

Track the below URL for one-step submission https://juniperpublishers.com/online-submission.php 